\title{
Abundance of ${ }^{13} \mathrm{C}-{ }^{13} \mathrm{C}$ bonding in biotic and abiotic ethane measured by a new $\mathrm{C}_{2} \mathrm{~F}_{6}$ method
}

\author{
KOUDAI TAGUCHI $^{1 *}$, TOMONARI YAMAMOTO ${ }^{1}$, \\ MAYUKO NAKAGAWA ${ }^{1,2}$, ALEXIS GILBERT ${ }^{1,2}$, YUICHIRO \\ $\mathrm{UENO}^{1,2,3}$ \\ ${ }^{1}$ Department of Earth and Planetary Science, Tokyo Institute \\ of Technology, Meguro, Tokyo, 152-8551, Japan \\ (*correspondence: taguchi.k.ab@m.titech.ac.jp) \\ ${ }^{2}$ Earth-Life Science Institute (WPI-ELSI), Tokyo Institute of \\ Technology, Meguro, Tokyo, 152-8551, Japan \\ ${ }^{3}$ Department of Subsurface Geobiological Analysis and \\ Research (D-SUGAR), Japan Agency for \\ Marine-Earth Science and Technology (JAMSTEC), \\ Natsushima-cho, Yokosuka 237-0061, Japan
}

\begin{abstract}
Doubly-substituted isotopologue could be a potential tracer for biogeochemical processes, though the study of ${ }^{13} \mathrm{C}$ ${ }^{13} \mathrm{C}$ isotopologue is limited [1]. Here, we propose a new fluorination method for measuring ${ }^{13} \mathrm{C}-{ }^{13} \mathrm{C}$ isotopologue of $\mathrm{C}_{2}$ molecules using a conventional isotope ratio mass spactrometer. Because fluorine has only one stable isotope, ${ }^{13} \mathrm{C}_{-}{ }^{13} \mathrm{C}$ isotope species in $\mathrm{C}_{2}$ molecules were measured as $\mathrm{C}_{2} \mathrm{~F}_{6}$ arising from the fluorination of $\mathrm{C}_{2}$ molecules. The method is applicable to ethane from natural gas samples but also to ethanol. Reproducibility of the whole protocol, including chemical modification steps and the mass spectrometry of $\mathrm{C}_{2} \mathrm{~F}_{6}$ is $0.14 \%$ for the $\Delta^{13} \mathrm{C}^{13} \mathrm{C}$ value. We applied this method to sevral $\mathrm{C}_{2}$ molecules: ethane from natural gas (thermogenic and abiotic), biologically derived ethanol as well as abiotic ethane produced by UV irradiation, spark discharge, Fischer-Tropsch synthesis and Gamma ray irradiation [2].

Ethane from thermogenic natural gas samples and biologically derived ethanol show a narrow range of $\Delta^{13} \mathrm{C}^{13} \mathrm{C}$ values varying from $+0.72 \%$ to $+0.90 \%$ relative to our tank $\mathrm{C}_{2} \mathrm{~F}_{6}$ gas. In contrast, putative abiotic ethane from Kidd Creek show significantly lower $\Delta^{13} \mathrm{C}^{13} \mathrm{C}$ value of $0.25 \%$. Also, the ethane synthesized by all the experiments show the low $\Delta^{13} \mathrm{C}^{13} \mathrm{C}$ values similar to the Kidd Creek ethane or even lower. Therefore, $\mathrm{C}-\mathrm{C}$ clumping may be useful to distinguish biotic and abiotic origins of $\mathrm{C} 2$ molecules.
\end{abstract}

[1] Clog M et al. (2018) Geochim Cosmochim Acta 223,229244. [2] Boreham C J et al. (2020) Radiatio Physics and Chemistry 168 , 